\title{
Shmuel Trigano (dir.), D'où vient la Torah ? Culture et révélation
}

Paris, Pardès 51, Éditions In Press, 2012, 187 p.

\section{Daniel Vidal}

\section{(2) OpenEdition}

\section{Journals}

\section{Édition électronique}

URL : http://journals.openedition.org/assr/26583

DOI : $10.4000 /$ assr.26583

ISSN : $1777-5825$

\section{Éditeur}

Éditions de l'EHESS

Édition imprimée

Date de publication : 31 décembre 2014

Pagination : 307

ISBN : 978-2-7132-2467-6

ISSN : 0335-5985

\section{Référence électronique}

Daniel Vidal, «Shmuel Trigano (dir.), D'où vient la Torah ? Culture et révélation », Archives de sciences sociales des religions [En ligne], 168 | 2014, mis en ligne le 22 mai 2015, consulté le 22 septembre 2020. URL : http://journals.openedition.org/assr/26583 ; DOI : https://doi.org/10.4000/assr.26583

Ce document a été généré automatiquement le 22 septembre 2020.

(c) Archives de sciences sociales des religions 


\section{Shmuel Trigano (dir.), D’où vient la Torah ? Culture et révélation}

Paris, Pardès 51, Éditions In Press, 2012, 187 p.

Daniel Vidal

\section{RÉFÉRENCE}

Shmuel Trigano (dir.), D’où vient la Torah ? Culture et révélation, Paris, Pardès 51, Éditions In Press, 2012, 187 p. 
$1 \quad$ Y a-t-il une bible avant la Bible ? Un temps avant le Temps? Une première fondation avant la fondation Première? Comment penser la relation entre les épopées babyloniennes et leurs accomplissements institutionnels, et le récit biblique ultérieur, ses généalogies, ses prophètes, sa Loi? Et si l'on en vient à la seule spécificité du Texte, la Torah, un autre questionnement se présente : qu'en est-il de la Révélation et de la « concrétude » du récit biblique, du «ciel » de la divinité, et de la terre du peuple juif? Deux ensembles d'interrogations qui s'enchaînent, de la trace archéologique, et de sa signification ambiguë, à l'interprétation de la Lettre, et sa promesse de vérité. Certains exégètes ont pu tenir pour scandaleuses les conclusions

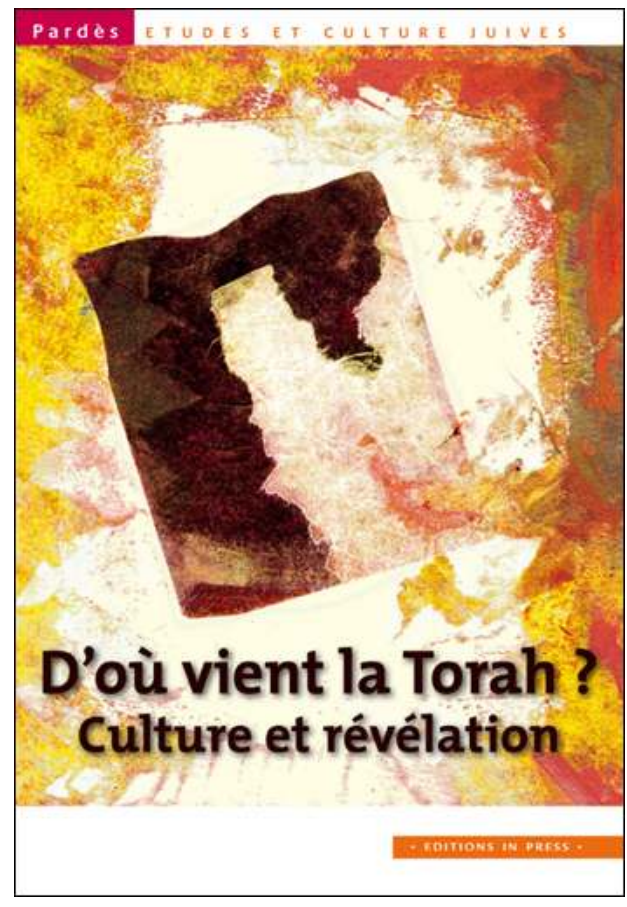
que les archéologues pouvaient tirer de leurs recherches. La moindre n'étant pas l'absence remarquable de signes témoignant de la présence du peuple hébreu en Égypte, et remettant en cause le récit biblique du retour vers la terre promise! À y perdre en effet son dieu et sa raison. S. Trigano propose cet exemple de difficile conciliation de l'invalidation scientifique des "faits", avec les événements relatés par la Torah, pour dire l'improbable compatibilité de deux lectures engagées en des ordres et conditions de sens sans mesure commune. Doit-on, pour autant, tenir pour vaine la quête d'antécédence ou le déchiffrement de comparaisons? Soit le Déluge, présent en l'épopée mésopotamienne de Gilgamesh, au troisième millénaire av. J.-C. En cent points comparables au récit biblique de Noé. Et en cent autres points, s'en séparant, selon l'analyse de Th. Alcoloumbre. Soit aussi bien le Code de Hammourabi (xviII s. av. J.-C), que l'on a pu dire "précurseur de la législation mosaïque ». Sur bien des points, à nouveau, proche du Décalogue, ce code de l'Alliance. La Bible et sa préhistoire? La Bible et son enracinement/dépassement païen? Mais faut-il penser en termes convenus d'héritage et de continuité, toute différence assumée ? Ou convient-il de penser à nouveaux frais le rapport entre deux ensembles civilisationnels, deux entités culturelles?

2 Ce que les cultures ont en commun, rappelle Shmuel Trigano, c'est une « expérience fondamentale et fondatrice", que l'homme vit pour "assumer et construire son existence ». Chaque moment d'humanité partage cette même épreuve, et la traverse avec ses propres mots, et ses propres hasards et nécessités. Cela pourtant ne suffit pas, qui réfère une "condition humaine" chaque fois inscrite dans une historicité particulière. C'est la question même de l'origine qui fait problème. Car chaque "mythe » est originel, avant que d'être original. En ce sens qu'il désigne non pas le " début », mais le " commencement » de ce qui se présente alors comme radicalement premier. Au reste, la Bible distingue bien ce qui, de naître en premier, n'est que premierné, quand celui qui vient après, le cadet, est dit aîné. Ainsi de Jacob, d'Abel, de Joseph, etc. Une « économie du commencement » se déploie ici, qui se fonde sur un brouillage 
de la temporalité. Cet effacement du principe d'antériorité est en relation, selon l'expression de Trigano, avec « l'absence d'image référentielle de l'être », qui renvoie à la conception du « retrait divin » comme fondement du monothéisme hébraïque : ce qui vient «avant» se retire, et la "présence » du divin est cette place vacante «dans laquelle l'homme surgit». Dans cette perspective, l'idée de création est « résolument non mythique », mais elle est le nom de cette " advenue » de l'homme sur le « défaut » de Dieu.

3 La question de l'origine, et de l'originel qui s'ensuit, soutient aussitôt ce que Raphaël Draï appelle «la revendication de la priorité exclusive». Mais lorsque deux cultures s'affrontent sur le thème de la préséance de leur principe fondateur, comment décider d'un ordre impossible de priorité ? Le recours à un comparatisme rigoureux ne suffit pas, pas plus qu'un constat d'homologies ou de résonances entre "imaginaires » en présence, ainsi qu'il en va de l'idée de justice dans la mentalité égyptienne et la pensée biblique. Il faut alors penser en même temps le foisonnement d'influences et l'impératif du commencement absolu, comme décision de franche rupture et de singularité exemplaire. Si le récit babylonien pose une dichotomie entre héros divinisé et homme ordinaire, le récit biblique dit la loi commune à tous et non réservée à une caste ou une élite. La Loi, donc: de quelle origine à son tour la créditer, qui la définisse comme prescription du commencement du monde? La Torah, céleste ou terrestre, demande S. Trigano ? "Fille de Dieu fiancée à Israël », ou résidant sur terre "parmi les Sages et non plus les Prophètes » ? Céleste, elle précéderait Moyse et jusqu'à la création, étant la Création même, une Torah " coéternelle à Dieu ", selon le courant apocalyptique juif. Terrestre, la Torah ne se peut que sous condition d'Israël. Loi, peuple et sol indissociablement conjoints, ainsi que le conçoit l'ascétisme rabbinique.

Mais peut-on demeurer en cette dualité de position? Livre du Ciel et de la Terre, propose Catherine Chalier, la Torah, «absolue et immémoriale » n'a pas d'origine en l'histoire. Toujours déjà-là avant d'être écrite, elle est « du ciel » en tant que le ciel est "l'infini, la transcendance, le "Séparé" ». Mais elle est aussi cette parole qui se joue sur terre, appel fragile qui s'entend dans la condition toujours neuve d'une écoute aujourd'hui et maintenant. Là se situe sans doute l'origine de la Torah, dans ce recommencement permanent de la parole qui s'y livre, et dans la présence du sujet qui la reçoit. C. Chalier ouvre ainsi une réflexion majeure sur l'irréductibilité de cette Parole, pour autant que chaque sujet lui « offre asile de sa propre intériorité ». À cette condition, la vérité du Texte est garantie. Il n'est de Loi que dans l'interprétation individuelle/collective qui en est faite, en chaque verset se conjuguant l'ordre de la spiritualité et l'ordre du fait en un seul moment de parole. En chaque parole, en effet, la Torah, cette "pensée d'En-Haut», selon l'expression de Michel Attali, s'offre comme « inévidence fondamentale ", à partir de laquelle - contre laquelle ? - le sens doit être dit. Il est en effet dans la Torah ce qui constitue «le don direct de Dieu », la lettre, le mot, le blanc - et l'ouverture au sens, qui ne devient effectif que dans l'étude qui ne cesse de s'accomplir. Du «fond des cieux» au «fond de l'intériorité», une relation privilégiée s'établit, qui fait descendre du ciel ce qui vient de la terre, et exhausser du sujet ce qui atteste du divin.

5 Qu'en est-il de la Révélation? Si le «révélationnisme» est bien au principe du fondamentalisme juif, et si par ailleurs la science, se faisant métaphysique, récuse tout sens ultime à l'existence, entre "créationnisme » et "physicalisme » Rivon Krygier évoque l'œuvre du rabbin Louis Jacobs, qui tente de concilier raison et religion, 
ressortissant pourtant de deux univers conceptuels incommensurables. Ou la possibilité d'appliquer au judaïsme une " pensée évolutionniste ", qui requerrait un argumentaire anthropologique ratant l'exception que représente le fait juif dans l'histoire, et contre elle. Seule une inversion radicale de la question de l'origine et de la question de la Torah peut engager la réflexion sur des voies nouvelles. Soit la sortie d'Égypte, "événement archétypal de l'émancipation individuelle et collective». Fait "historique ", dûment certifié par les témoignages archéologiques? Ou élaboration mythique participant d'un récit de fondation? Si l'on veut échapper à cet insoluble dilemme, sans renoncer a priori à l'historicité non plus qu'au mythe, il ne faut pas partir d'un temps de l'origine perdu dans un passé indicible, mais, procédant en sens inverse, aller de ce qui se passe dans le présent du peuple juif et en chacun des sujets qui le composent, pour en venir véritablement à l'origine, c'est-à-dire aux « fondations de l'autorité de la Torah». L'origine sera pensée comme présent absolu. Ou le présent comme origine toujours recommencée. Alors l'effet est la preuve de la cause, analyse R. Krygier. Et cette préséance du présent engage toute littérature biblique, et toute lecture de la Torah, à valoir interprétation singulière de la Loi. La révélation serait alors l'accomplissement, humain-trop humain, de la Lettre, par-delà l'histoire et le mythe. 